\title{
Owning Ourselves and Encountering Others: Authenticity, Indifference and Desire
}

\author{
KAREN RobERTSON
}

The question of the availability of normative guidelines for human action in Martin Heidegger's work has been a long-standing site of controversy. Indeed, his work is often labeled antinomian in light of the fact that it precludes and undermines the priority of positive law in accordance with the insight that anything like a first principle of thought fails to keep the thinking of Being alive. ${ }^{1}$ Nevertheless, strong efforts have been made to draw out the normative aspects of Heidegger's work, and this should come as no surprise given that Heidegger's philosophy is, at least in Being and Time, concerned with the question of how to live, and because much of his other work radically criticizes the modern, liberal account of how to live. ${ }^{2}$ Whatever their motivation may be, those who claim that there are resources in Heidegger's work for ethical and political thought must justify such use of his scholarship in light of Heidegger's own political involvement with the National Socialist party. Heidegger's work is often criticized as a resource for political or ethical thinking. It is also taken to task for a lacking in praxis, and of consequently having nothing to offer to a practical approach to human 1 ife. ${ }^{3}$ In this paper I demonstrate that there are normative guidelines for behavior in Heidegger's work, but that rather than taking the form of explicit law these guidelines require that we respond self-critically to the way in which the enactment of our individual identities has been enabled by our participation in 
the public, communicative structures that define community. ${ }^{4}$ I will argue that the involvement of others in Dasein's self-enactment has implications for Dasein's authenticity.

The normative implications I identify amount to the necessity of responding adequately to the fact that the terms through which any human identity is expressed are a product of the communicative cooperation of many: terms of identity should apply to all in the same way, and, because these terms are a product of all, they are the responsibility of each individual. Throughout the paper, I identify the two normative dimensions to which I just referred-equal access to the significance of terms and responsibility for those terms - as the two supplementary demands of authenticity. I argue further that our interpersonal relations can awaken us to these dimensions of authenticity, and I employ Sartre's account of desire to illustrate this. In so doing, I hope to show that while for Sartre consciousness responds to the other as a contingent fact, and for Heidegger Being-with is part of Dasein's own structure, the two accounts can nevertheless be brought into productive dialogue around the supplementary demands of authenticity I have identified. $^{5}$

On my view, the incompatibility between Heidegger and Sartre is productive for an analysis of our current social and political contexts. Sartre's insistence on the priority and distinctness from others of consciousness allows me to illustrate that interpersonal relations remain sites that disclose to us the supplementary demands of authenticity in modern contexts that are organized around the presumption of the autonomy of the subject. ${ }^{6}$ As I present it, Sartre's insistence on the failure of desire is reflective of his insistence on the distinctness of consciousness. I argue that while Sartre's account of desire points to intersubjective dimensions that are compatible with (my presentation of) Heidegger's account, Sartre identifies our access to these dimensions as sites of conflict rather than, rightly, as the irreducible demand to negotiate 
with each other for the sake of the constant realization of shared terms and the contexts they subtend. Due to my way of negotiating the tension between Heidegger and Sartre, while I am most interested in the disclosive potential of interpersonal relations, I shall also, following Sartre, acknowledge how our possibilities of cooperation are always, equally, potential sites of conflict. Thus, the possibilities of disclosure inherent in our interpersonal relations are inevitably accompanied by the risk of conflict.

My paper has three sections. In the first section, I draw on Heidegger's analysis of BeingGuilty to argue that our everyday experience of ourselves as selves depends upon our identification with public terms of identity such that we are always already intersubjectively articulated to ourselves in the terms of public life. Next, I connect this account of intersubjectivity with an analysis of Dasein-with and Being-with in which I explore how we construct our identities in relation to individual others. Through this analysis I argue that because the sense of self available to us is dependent on the interpersonal dynamic through which terms of public identity arise, we are irreducibly responsible to particular others. Further, I argue that this responsibility requires that we attend to the way that particular individuals identify with, and represent themselves in keeping with the terms of public identity. Though, for the most part, I will describe this mode of attendance in terms of a reciprocal relation with the other, it should be noted that it is not necessarily a question of equal exchange, but rather of recognizing and responding to the other's singular experience of our intersubjectively constituted projects. In the second section, I claim that Dasein's responsibility to others implies a responsibility for the contexts in which concrete encounters occur, but that despite our inherent responsibility, the worldly contexts we inhabit tend to develop in ways that increasingly diminish our tendency to respond to the other's irreducible claim to recognition. Because, as I will argue, our agency and, 
consequently, the possibility of our freedom, is accomplished only through the communicative structures (Language, Law, and so on) by which we enact ourselves, our failure to recognize the other amounts to a reduction of agency both on our part and on the part of the others with whom we share a world. While the fruit of this discussion has moral implications, these implications should be understood as descriptive of our ontological situation, and thus, as implications that would hold whether or not they accord with common accounts of morality. ${ }^{7}$ My third section turns to Sartre's account of desire in Being and Nothingness to demonstrate that the most basic ways in which we fail to recognize one another correspond to a denial of necessary structural aspects of the experience of encountering one another. I describe three such aspects in order to show how the interpersonal dynamic at work in desire may offer itself as a corrective to the prevalent ways in which we fail to recognize one another adequately in our social world, even while the risk of conflict remains.

Overall, then, I am claiming that human freedom depends on the cooperatively established structures of communication that constitute community, and that such structures themselves are nothing but the collective interpretation and articulation of the given terms of our relations. That is, they are the result of the way our isolated experience makes us dependent on the equally isolated experience of others. Moreover, I am claiming that because the possibilities of authentic freedom within a community are themselves grounded in our relations with one another, we are responsible for maintaining worldly contexts that can accommodate the interpersonal dimension necessary for an authentic identification with the terms of public life, and only secondarily responsible for any particular aspect of community life. ${ }^{8}$ 


\section{Responsive Recognition in Dasein-with and Being-with, and Guilt}

In this section, I will argue that individual identity is accomplished only in communication with an other, and that authenticity is realized, consequently, in how we relate to others. ${ }^{9}$ Although Heidegger's account of authenticity is often construed as Dasein's retrieval of itself from a thoughtless self-identification with the terms and opinions of public life- thus construed as an individual endeavour-I am here demonstrating that such a retrieval is dependent on a reconception of one's relation to others. ${ }^{10}$ Authenticity can be realized only by acknowledging that, as we will see, any worldly self-disclosure is availed by the Dasein-with of others, that is, by how others appear. ${ }^{11}$ A reconception of relations to others involves, therefore, a modification of one's adoption of the terms of public life by correctly perceiving them as modes of relating which have to be cooperatively enacted by two beings who necessarily exceed the terms by which a relationship is recognized.

Our responsibility to others corresponds to the fact that worldly structures of communication are themselves a response to the necessity and inadequacy of self-expression. While our sense of self is a product of the irreducible necessity of self-expression for the development of self-consciousness, it is, at the same time, a result of the inherent inadequacy of any attempt at self-expression. The terms of public life embody this tension by being both necessary for and inadequate to self-realization. The inadequacy of worldly terms is revealed by what Heidegger calls "Being-guilty."12 According to Heidegger our existence is such that we are selves who are singular sites of innumerable possibilities. In every case, we have projected ourselves onto the one worldly possibility that constitutes our life. We must accept this restriction of possibility as essential to our existence, or we will always experience worldly terms as only ever inadequately encompassing the nature of our existence. ${ }^{13}$ That is, we must accept 
our own finitude in order to grasp the appropriateness of worldly terms to our way of existing, and we must understand that our very existence is defined by the process whereby definite terms and possibilities become meaningful only in relation to contexts that exceed them. In order to experience our possibilities as adequate to an experience of self, we must understand our existence as a process of realizing definite meaning. We must also own up to the meaning that constitutes the specific worldly terms through which we articulate our existence. ${ }^{14}$ Through our individual experience of the weight and necessity of our projects we, somewhat contradictorily, are compelled to recognize the role of others in the ontological constitution of the terms through which we realize our projects, and we are compelled to recognize that recognition itself is integral to the possibility of experiencing our projects as adequate to our experience of self. Further, it is this demand that discloses the supplementary dimension of authenticity, which requires that we own up to our dependence on and responsibility for others, and the context we share.

The supplementary demand that we respond to others is reflected by the inadequacy of the experience of self we have in isolation. Indeed, when we only thoughtlessly adopt public terms, we encounter our own singularity as the experience of an inexpressible self that has no definite or recognizable characteristics, but which is, nonetheless, the condition of possibility of the fact that we are the selves we are; the experience of the inadequacy of public terms is connected to the experience of self in which the self is recognized as a nullity. Heidegger refers to this nullity as the basis of Dasein's primordial Being-guilty; Dasein is constitutively guilty because it is only as not equivalent to the possibilities it lives out that an experience of self arises. Because, as such nullities, we depend on worldly terms for our self-articulation, our being a nullity means "never to have the power over one's ownmost being from the ground up" (BT 
330; SZ 284). ${ }^{15}$ We rely irreducibly on the possibility of communicating ourselves in terms we alone did not develop because, to properly be ourselves, we must enact ourselves in worldly terms. For Heidegger, the inevitability of our relinquishing ourselves to terms that are never originally our own is the existential meaning of "guilt."

There are two consequences of an authentic recognition of the fact that public terms of identity offer to us meaningful possibilities of self-expression. The first consequence is that when one recognizes that the only self that one can be is a projection of oneself-as constituted by many possibilities - onto one worldly possibility, one understands that to be a self corresponds to having a perspective on one's own self, and that this perspective is authentic when it properly recognizes public identity as expressive of itself. ${ }^{16}$ The second consequence follows from the first: once one's worldly self is perceived as a self-expression that could have been otherwise, it must be perceived as a self who has been chosen. We recognize ourselves authentically when we own up to the fact that our public identities are expressive of the very selves we have, in principle, chosen to be. Experiencing oneself as the source of this choice amounts to a recognition of one's agency.

Developing an authentic relationship to oneself requires developing authentic relations with others because public terms are the expression of collective possibilities, and constitute, within a community, a network of possibilities that could have been otherwise. Heidegger writes;

factically, however, any taking-action is necessarily "conscienceless," not only because it may fail to avoid some factical moral indebtedness, but because, on the null basis of its null projection, it has, in Being-with-others, already become guilty towards them. ( $B T$ 334; SZ 288)

We are essentially guilty with respect to one another because we have collectively made it the case that only certain possibilities are available to any of us. To recognize specific possibilities as 
chosen is, in principle, to recognize the exclusion of other possibilities. Thus, in the same way any one of us is characterized by not having actualized innumerable possibilities, we are guilty towards others because the terms through which we are able to acknowledge one another could themselves have been otherwise. ${ }^{17}$ Authenticity thus consists not only in recognizing that we bring about the public terms of our world cooperatively, but also in recognizing that our role in this bringing-about means that how we own up to our choices and actions affects the possible choices of others.

In relation to the fact that the terms of public life arise as a network of shared possibilities, it is necessary to address the communicative dynamic through which such a network arises, and, in the interest of developing our understanding of authenticity, to determine also what is required of us in light of it. Heidegger's analysis of Dasein-with and Being-with, I contend, demonstrates that the possibilities we acquire with and for one another are always the result of communicative self-expression. Understood in this way, Heidegger's account enables a rich understanding of the cooperative process by which terms of public identity arise. As we will see, we, as individuals, cooperate in the establishment of the constitutive terms of individual identity because our relations with one another are essentially constituted by the structure of communication. Indeed, communication is only necessary in the first place because of that aspect of ourselves that remains inherently indeterminate; as much as we are involved in the world, we also always experience ourselves in terms of the fact that we exceed this involvement. As Heidegger describes this experience of excess, an experience of the world is "tied up with Dasein's ownmost Being — a Being which can essentially have no involvement, but is rather that Being for the sake of which Dasein itself is as it is" (BT 160; SZ 123). The Being referred to here is Being-with, and the quote points to the fact that that our existence is originarily constituted by 
an inherently incommunicable experience of itself that is simultaneously an inherent recognition of others with whom it can communicate, and with whom it can come to enact its otherwise inaccessible and inexpressible self. ${ }^{18}$ We grasp the nature of our own existence only when we grasp the necessity of others for such an existence; when we realize that our existence consists in our being communicable, we realize that the significance of our existence depends on the recognition of others who are also essentially incommunicable.

To recognize another as one with whom I can communicate is to recognize that other as one for whom aspects of the world are significant in the same way that they are significant for me. On the basis of our exclusive yet interconnected experiences of significance, communicative interaction involves an exchange of terms - words, gestures, signs, etc. - grounded on and enabled by the shared meaning of those terms. Again, these terms must not necessarily take the form of strict reciprocity; they may, and most often will, especially in less personal contexts, but what is most essential to communication is a recognition of the "sameness" of the other's alterity, and consequently, of the other's own singular dependence on shared terms for their own authentic projects. For myself as for the other, what or who I can present to others is always determined by the singular inaccessibility of myself and others, such that terms of participation are our ways of expressing ourselves to others. These terms encompass the range of relations that spans between the drastically impersonal recognition of another as, for example, that stranger on the other side of the street, and the recognition of a partner or good friend with whom I share intimate aspects of my life. Terms of participation constitute the kinds of relations we can have with others, and identify the context within which we will relate to others, because these terms enable participation in the different types of relations that are possible in a community. ${ }^{19}$ 
Given this, my self-knowledge depends on my capacity to come to know others, and this capacity itself depends on my ability to be responsive to others. The shared meaning of public terms is available only through participation in the life of a community because it is as members of various types of communities that we are able to represent ourselves and thereby enact an identity. Despite this, even within such communities, no one of us ever encounters the self we present to others. When we encounter others, we encounter others as Dasein-with. We encounter others as they are for others, and, consequently, in a way that we will never encounter our own selves. Despite never encountering the self I am for others, I am a self for others. I can come to know this self only by coming to know the world in which I encounter others. Thus, I come to know myself only by participating in the terms that circumscribe the being-together I share with others. My self-knowledge is therefore not a matter of coming to understand public terms in a reflective way. That is, I don't understand myself as a friend or neighbour by coming to be familiar with the definitions of the terms friend or neighbour, but, rather, I come to understand myself, and the terms of participation that are available, precisely by participating in relations that are contextualized by these terms.

In order to realize the full potential of self-enactment in relation to others, and the consequent possibilities of self-recognition, we all must be consistently and self-critically aware of the fact that our existence is largely defined by our relations with others. We can own up to and take responsibility for this awareness by ensuring that we do not prioritize our own experience over the possible experience of others, a tendency that often takes the form of failing to acknowledge the other's significant experience of the terms through which I recognize myself. ${ }^{20}$ For example, I need to recognize that the effort I put into being a friend is matched by the unique effort on the part of another insofar as that other is a friend. If someone self-describes 
as my friend, I need to understand that that person's behavior will be, in part, determined by an experience from which I am excluded, but which I can understand. My capacity to be aware of the degree to which I acknowledge my involvement in cooperatively-constituted relations is my capacity to be self-critical, and this capacity allows me to develop an effective agency that is itself derived from the understanding I gain from the experience of my concrete self-enactment in relation to others. ${ }^{21}$ My own perspective is thus supported and enabled through my recognition of the perspective of the other, hence enabling my experience of the adequacy of worldly terms. In other words, my agency and my freedom depend on my understanding of the terms through which I enact them, and I cannot understand such terms without understanding their rootedness in the ontological co-constitution of myself and others.

My potential for authenticity is consequently supplemented by the potential inherent in my relation with others, and it is by realizing this potential that I discover that my agency is such that my own singular opportunity to act, and have an effect in the world, is an ability to relate to others in determinate and contextualized ways. In keeping with this dynamic, my potential for authenticity, and the first supplementary demand of authenticity, consists largely in my capacity to exercise a consistency between my interpretation of others and my own self-recognition.

\section{The Demands and Failures of Communication}

Up to this point, I have argued that communication is possible because it occurs between selves who have perspectives on themselves and who interact by holding the fecundity of a particular perspective in reserve so as to express something determinate and communicable. I have also emphasized that communicative interaction through worldly systems of communication amounts to our participation in the world, and I have explained that terms of 
participation amount to the particular types of identities we are able to adopt with respect to one another. Finally, I concluded that authenticity consists in the ability to recognize the fact that we must afford to the other the significance we afford to our own identity because it is only by doing so that we are able to actualize the potential for agency that corresponds to our experience of ourselves. I will now argue that societal contexts instigate the most ubiquitous forms of misrecognition, and claim that because of this authenticity consists also in answering to the demand to take responsibility for the shape of societal contexts.

While having an identity demands that I participate in public contexts, public contexts are not always conducive to authentic life in community. The common world-a world constituted in and through communication - is a world that may consistently fail to provide settings that enable and cultivate the human capacity for authentic self-enactment. The second demand of authenticity consequently involves taking responsibility for the failures of recognition that tend to occur in the worldly contexts by taking responsibility, generally, for a shared community. I will identify four failures of recognition that are themselves failures to own up to the inherent structure of communication, and I will demonstrate that these failures of recognition can be attributed to three pervasive characteristics of life in complex societies. ${ }^{22}$ These characteristics, I contend, cripple the potential for freedom available to us in community because they encourage the common failures of perception that are a product of more pervasive social failings. ${ }^{23}$ While the failures of communication I have identified may occur in contexts that differ from our modern, liberal ones, my aim is to establish a connection between these failures and pervasive features of our contexts. Indeed, it is for this reason that, in the subsequent section, I employ Sartre's account of desire to argue that interpersonal relations can reveal how our preconceptions of ourselves as isolated subjectivities tends to encourage conflicts as well as failures of 
recognition, and that these relations also provide us with the opportunity to reconceive of ourselves and of our relations to others, thus enabling our potentiality for authenticity.

In keeping with the analysis in the previous section, the type of recognition at stake does not reduce the other to the fixed terms of the world, but is rather akin to what Heidegger calls "leaping ahead": "This kind of solicitude pertains essentially ... to the existence of the other, not to a what with which he is concerned; it helps the Other to become transparent to himself in his care and to become free for it" (BT 159; SZ 122). ${ }^{24}$ By leaping ahead we help the other be free by helping him realize that his very self is at stake in his actions in a shared world. ${ }^{25}$ While in the previous section we saw that an adequate recognition of the other supplemented our capacity to experience our possibilities authentically, in this section we shall see that this recognition can be enabled only by confronting and taking responsibility for the pervasive features of our shared contexts. Thus, helping the other be free, I contend, includes taking responsibility for the contexts in which we interact with one another, and in endeavoring to ensure that such contexts encourage a communicative interaction with the other rather than an attitude that is characterized by indifference, and, by consequence, the loss of an awareness of the other's contribution. If we endeavor to recognize the other as communicating, we must not only acknowledge the other's freedom, we must also ensure that our shared context of communication enables freedom. ${ }^{26}$

There are two aspects of freedom at work in the complexity of structures available to us. One aspect refers to the concrete, everyday forms of freedom which are the freedoms afforded to us by the world in which we live. These forms of freedom might include the fact that we can chose to walk or take public transportation (and that, in either case, we can expect to do so with a high level of safety), or the fact that an individual can become a teacher or a waiter or a plumber. The second aspect of freedom refers to how we may or may not take up these concrete freedoms 
available to us, seeing them accurately as sites in which we enact ourselves, and in which others enact themselves. It is this second aspect to which the failures I have identified correspond. While these freedoms are rooted in our irreducible relatedness to one another, they are, nevertheless, concrete, ontic possibilities that have an effect on our existential involvement. Equally, the failure to realize the second aspect of freedom is an ontic or existential failure which occurs because the specific determinations of the first aspect of freedom-the concrete contexts available to us - make it the case that our every day encounters with others are deeply familiar and, therefore, easily mis-recognized. Thus, while the failures I will articulate are rooted in our ontological relatedness, our ability to respond to them does not necessarily lead to authenticity, but is, at the same time, a necessary aspect of it.

The first potential failure I have identified is a failure to recognize the contribution of the other to the context in which we find our acts to be meaningful. This failure occurs when we treat our own progress or success as something that we alone have accomplished. This false sense of independent accomplishment amounts to a blindness to all the people and institutions on which we depend for our self-realization, and this blindness is a failure to recognize the contributions of the others with whom we share, or have shared our world.

The second failure is a failure, on the part of individuals, to recognize that the experience others have is like our own experience in that, like each of us, others have an "interior" they cannot express. That is, I may view others only in terms of what they do instead of interpreting their actions as a result of their specific experience of being engaged in the world. This may result, for example, in the misapprehension of the satisfaction or dissatisfaction of others with their situation by assuming that the other may be more resigned to their role than we may be, and that they may, consequently, suffer less from it, or enjoy it less than we might. With this failure, 
we justify an indifference to the plight of the other by denying the uniqueness and significance of the other's suffering, the other's efforts to overcome obstacles, or the other's satisfaction in something well-deserved.

We may fail in a third way by failing to recognize that we are the site for the other's expression of freedom, and that we need others to express determinately our own freedom. When someone acts in the world, the meaning of that action is not determined by that person's private sense of reality. Rather, an action becomes a meaningful act in the world only when it corresponds to shared meaningful contexts, and when, as corresponding, it is recognized as a meaningful instance of self-enactment. Unless an act is recognized by others, it remains a bare physiological fact and does not become an instance of meaningful self-expression. This does not mean that an action has to be immediately perceived. If this were the case, then writing, for example, would not be a form of expression. Rather, it means that an act must lend itself to communication by entering into shared contexts according to terms established in cooperation. This necessity is as pressing for any one of us as it is for the other, and a failure to recognize this is a failure to recognize that our communication is an enactment of our freedom because communication amounts to the ways in which we cooperatively increase our ability to enact ourselves.

Finally, the fourth failure that can occur is the failure to recognize our own freedom. This happens when we find ourselves so immediately wrapped up in, and influenced by, the terms of the world that we fail to recognize that we are able to be the author of our actions only through worldly terms, and that, far from limiting us, it is through our internalization of worldly terms that we are able to express our freedom. The terms of the world are not limiting and inescapable; rather, they enable free and responsible participation in a meaningful context. 
These four failures have to do with the risks attached to specific social formations of a society that, in principle, enable an enormous amount of freedom. Further, each one of these failures has to do with a blindness towards an aspect of the way that we cooperatively establish our identities in terms that have themselves been cooperatively established. I will now explain that this type of blindness is caused by how our perception has been shaped by pervasive characteristics of our shared social situation. In the particular social matrix available to us, we may or may not accurately perceive the terms of identity that are available to us as sites for the expression of human freedom. Instead, the specific concrete contexts available to us make it the case that our everyday encounters with others have certain freedom-limiting characteristics, which I will also identify. It is for these characteristics that we are responsible according to the second supplementary demand of authenticity. It should be noted that insofar as I am claiming that we must take responsibility for our community, I am claiming equally that we must take responsibility for the way in which others tend to perceive the world.

The first pervasive characteristic of shared contexts is that others are perpetually encountered as indistinguishable and persistent. Everyday contexts are able to accommodate the pervasiveness of others, but only by organizing things in ways that do not require individuals to interact with anything but well-established and predictable modes of communication. In this situation, it goes unrecognized how others minding their own business contribute to the possibility of being able to independently realize projects. Shared, meaningful contexts consistently invite the presence of others without demonstrating that this very openness functions by perpetuating an attitude towards others that is characterized by a blindness to particularity and contingency. An appropriate response to others would involve a sensitivity to their implicit participation in our projects by way of our shared contexts. 
The second characteristic of our shared environment has to do with the quality of givenness through which the terms of our shared world appear. Because terms appear as given, it may not be recognized that the meaningful terms of appearance were developed by people, or that they could have been different. To experience worldly terms as inevitable and unquestionable to is see them as the ultimate expressions of what it means to be human and, relatedly, to see ourselves as fully reducible to those terms. This corresponds to a sense of alienation from oneself that can occur through an internalization of the terms of the world when this internalization is unaccompanied by a recognition of the way in which these terms enable freedom. In failing to see that the ways in which we enact ourselves could have been otherwise, we also fail to see how these terms do in fact allow us to become determinate selves in the world, and that this determinacy is necessary for the type of self-enactment that is an expression of freedom.

The final pervasive characteristic of our shared, meaningful contexts is a failure to recognize that the inaccessible internality of the other is the condition of possibility of freedom and communication. In failing to recognize that the other must be in reserve and, consequently, must escape me in order for there to be any communication at all, I fail to see that the complex constitution of our shared world is built on an inability to know the other and that this constitution is almost inevitably doomed to the type of inadequacies I have described.

The four failures of communication that I have described-blindness to the contribution of others, blindness to the significance of the other's experience, blindness to myself and the other as sites of freedom, and blindness to my own freedom-result from perceptual tendencies that are encouraged by three pervasive characteristics of modern life: contexts that accommodate many, the apparent givenness of terms of identity, and a lack of responsiveness to why we have a 
world at all. The perceptual tendencies that result from the three pervasive characteristics are tendencies that can be corrected. Indeed, insofar as authenticity demands that we ameliorate these contexts, it is the perceptual tendencies on which we rely that need to be altered. Let us now consider how it is that our interpersonal relations offer themselves as resources for correcting the perceptual tendencies encouraged by our current shared contexts.

\section{Sartre and Interpersonal Relations}

While, on my account, any shared context is ultimately rooted in Dasein's projective selfunderstanding, these contexts are also concrete realities in which we may participate well or poorly, as well as with or without an adequate ontological understanding of our Dasein. Indeed, in the previous analysis, I traced features of modern liberal societies that are organized around an individualistic understanding of human beings. I want now to illustrate how interpersonal relations, especially the experience of desire, offer resources for correcting modes of blindness characteristic of such societies. To this end, I shall illustrate how the experience of desire undermines characteristic features of modern, liberal contexts - the anonymity of others, the givenness of terms, and the assumption that we are subjects fully present to ourselves. I shall explain how interpersonal relations open us up to the supplementary demands of authenticity I have identified; unlike impersonal, worldly encounters, interpersonal relations explicitly demand that we familiarize ourselves with what the other's experience is like, and that we take this knowledge into account insofar as we contribute to, and take responsibility for, the atmosphere of our encounters. While interpersonal relations consequently offer a real experiential education into how to answer to the two demands of authenticity, they are also subject to the preconceptions about ourselves and our relations to others that are pervasive in society at large. I 
contend that these relations can accommodate both our (inadequate) preconceptions and the possibility of overcoming them when we embrace the cooperative nature of our relations, and that, consequently, our interpersonal relations are contexts in which we can ameliorate our capacity to recognize and respond to the demands of authenticity. In order to demonstrate this, I will employ Sartre's account of desire from Being and Nothingness. ${ }^{27}$ I will argue that Sartre's account of the way consciousness is originarily exclusive of others resonates with presuppositions characteristic of modern liberal societies and that his account of the conflictual nature of our relations to one another can give way to a recognition of the way that conflict derives from our (mis)apprehension of our the discrete character of consciousness.

As I see it, Sartre's and Heidegger's accounts of the open-endedness of the individual (as transcendence, or as disclosed by anticipatory resoluteness) are compatible enough to allow the correctives implicit in Sartre's account to open the way to an understanding of Heidegger's ontological account, and thereby, to come to understand our isolatedness as our point of entry to the world, rather than as our fated circumscription by its terms. Indeed, as I shall demonstrate, the motivations that lead to the failure of desire are equally the reasons that desire can open us to the way in which our contexts are cooperatively constituted. By demonstrating that the features of desire which are constitutive of its failure are equally the features that disclosed the shared and contingent character of the world, I hope to show that Sartre's account can orient us helpfully towards my Heideggerian understanding of shared contexts and terms as sites of negotiations necessary for the authentic self-appropriation of each of us.

Let us now draw on Sartre's analysis to consider how, given the prejudices of our given world, prejudices that, as we have seen, are related to the supplementary demands of authenticity I have identified, we might begin to reshape our experience of the other and, thereby, to see that 
our relations with one another force us to negotiate continually the terms of our shared reality. I have identified three aspects of interpersonal relations that are relevant to both Heidegger's and Sartre's account, and which can function as correctives to the pervasive features of our shared contexts. The first aspect is that interpersonal relations disclose the sharedness of the world and, thereby, mitigate our indifferent attitudes to anonymous others; the second is that they disclose the fact that particular and determinate worldly forms of our relations to others are always contingent and thereby, mitigate our tendency to assume the givenness of terms; and the third is that they reveal that our own isolatedness from the world is constitutive of our freedom and, thereby, mitigate our tendency to disavow our own unrealized nature and our consequent relatedness to others.

In the first place, desire reveals that our experience of the world is primarily an experience of the site in which we interact with others rather than a site assigned to individuated existence. ${ }^{28}$ As Sartre writes, "desire is not first nor primarily a relation to the world. The here appears only as the ground for explicit relations with the other" (BN 510). Though, for Sartre, desire is a response to the risk of objectification that accompanies the other's look, its occurrence discloses our capacity to share a world. Meanwhile, the risk inherent in it forces us to acknowledge that, contra the prevailing tendencies of our liberal contexts, others are unique and particular contributors to a shared world, rather than anonymous ones to whom we can be indifferent. According to Sartre, the experience of the world enabled by desire is inspired by an attempt to control the indeterminate and unpredictable threat of the other's subjectivity by limiting our own tendency to transcend the world in pursuit of our projects and, thereby, experience the other as mere object $(B N 497)$. On this account, our perception of the threat the other constitutes is inspired by our sense that the other is foundational to us while irretrievably 
separate from us. What this presupposition overlooks is the necessity of conflict, divergence, and alterity for a shared world. Thus insofar as desire is both inspired by an experience of conflict, and is an attitude towards it, desire can transform our experience of conflict into an experience of the possibility inherent in our necessary negotiations with one another by disclosing the world that arises between us. This perceptual transformation requires that we disavow the exclusive character of our experience of the world and of ourselves, and that we embrace ongoing negotiations with others as constitutive of our experience of the world. By embracing the possibility to which desire opens our eyes, we allow the experience of desire to counteract our tendency to interpret our accomplishments in the world as independent accomplishments, forcing us to recognize that the sites of our projects, as well as their particular determination, are dependent upon our being originarily disposed to the presence of others. In this way, desire reveals that the indistinguishability and persistence of the other is, in fact, a misapprehension of the fact that we depend on each other for even those contexts in which it is possible to treat one another with indifference.

Secondly, the dynamic of desire challenges our tendency to recognize others as reducible to the fixed terms of the world, and, thereby, calls into question the second pervasive tendency of our world: the apparent givenness of terms. Here too, the very threat that arises on the basis of the other's subjectivity is equally the means by which we may find ourselves inspired to reconceive of our relatedness to others. Sartre explains that in the experience of desire, we aim for a pure experience of our contingent facticity in order to allow it to be the medium though which we invite the other to incarnate their free subjectivity and, thereby, grant us access to their freedom (505). When conceived of from the perspective of conflict, sheer contingency remains the goal. At the same time, the experience of desire reveals that sheer contingency is always 
more than that; contingency is the fecund realization of a richness that surpasses both myself and the other and on which we both depend. As Sartre explains, desire precedes any identification of how the body is sexed; it is not a body that we first desire, rather we first desire and through this desiring, the body appears to us as sexed ( $B N 499)$. Thus, the sheer contingency to which we reduce ourselves is always the realization of the irreducibility of the other. In desire, the sexual character of backs, torsos, thighs, and so on shows itself in an ambivalent determinacy; it is your body that I desire, but the specificities of your body are desirable to me because I first experience a desiring inclination toward you. Thus, though we may aim for pure contingency due to our perception of a threat, once we desire, we may overcome this perception through the experience of the determinate contingency of the factical body as both necessary and inadequate to the expression and realization of desire. Thereby, we may experience givenness as the necessary and inadequate response to a more fundamental relation. The experience of desire, therefore, mirrors for us the way that worldly terms are not primarily normative and static, but rather are the contingent means by which we express ourselves in relation to one another, and are inherently transformable because, at root, these terms are ways of responding to something that exceeds representation. Perceiving that terms could have, and can be, otherwise reveals that we are responsible for the determinate form of the terms we currently employ. This discovery leads to an experience of responsibility, which mitigates the potential alienation to which worldly terms give rise.

Finally, desire reveals that in order to communicate with the other, the other must be one who is free like me and who will, consequently, always escape me. In this way, desire reveals to me that my own unrealizable self is constitutive of my authentic freedom and mitigates the tendency to disavow our own authentic projects of self-realization with and through others. Thus, 
I recognize the third pervasive feature of our modern contexts - the tendency to overlook our own freedom - by recognizing that my desire for the body of another takes the form of an address, rather than direct communication. As Sartre writes, desire "is addressed not to a sum of physiological elements ... but to a form in situation" (502). When I address myself to the other, I encounter my experience as shaped by the other's situation. Further, insofar as this experience is inspired both by the inaccessibility of the other and by my own lack of foundation, this very lack both opens me to, and reveals my dependence on, the situational character of the inaccessible aspect of human self-consciousness. While the threat of conflict may inspire me to encourage the other to reduce the freedom implicit in the other's situatedness, I can, equally, embrace this possibility of conflict by coming to understand my situation as inadequate without my recognition of the other. Desire can encourage this embrace by disclosing how the perspectival character of the other's being in situation mirrors and complements my own and, only in this way, offers to us an experience that exceeds us both. The experience of the excess availed by the other in situation can encourage me to acknowledge my own inaccessible self as my means of access to a reality that exceeds me, and, only thereby, grant me resources for my own authentic self-realization.

Through the experience of desire, especially through the features wrapped up in its failure, interpersonal relations demonstrate that there exists a need to maintain a world that is understood as the site and product of communication, and, consequently, as a place that is irreducibly shared and inextricably part of each of us. I hope to have demonstrated that Sartre's account of desire is helpful for coming to understand how our interpersonal relations can offer themselves as sites in which we can begin to overcome the habits ingrained in us by the shape of our modern liberal environments. According to my account, Sartre's position aligns itself with 
perceptual prejudices characteristic of such environments, while the aspects of his account of desire that ultimately lead to the failure of desire reveal that we must see shared contexts as reflective of the irreducibility of ongoing negotiations with others; the supplementary demands

of authenticity - the recognition of the other, and our responsibility for shared contexts - are coextensive with an understanding of how we only ever find ourselves in shared contexts, and how we need to meet the demands of these contexts and the others by whom they are constituted in order to own up to the features of our otherwise inadequate and isolated Dasein.

\section{Conclusion}

Throughout the course of this paper, it should have become increasingly clear that it is the particular perspectival nature of our experience that makes it the case that we can both fail to recognize one another, and that we have the potential to develop our freedom through the appropriate recognition of one another. Our communities, then, and their constitutive terms of participation, are themselves a product of both of these aspects of experience. Only a perspective essentially informed by innumerable possibilities has the necessary creative resources to maintain a world, and only a perspective that can fail to attend to possibilities as such has the focus necessary to resolve upon any one perspective. ${ }^{29}$ It is, thus, as essentially in reserve, and as constituted by innumerable creative possibilities, that we adopt the determinate world upon which we project ourselves. It is fitting, then, that the interpersonal relations in which we engage have the potential to remind us of the very source of community life. In particular, it is fitting that the interpersonal dynamic that corresponds to our experience of desire demonstrates that the dynamic phenomenon of authenticity is a phenomenon that is ours to enact only by coming to find ourselves as the source of our orientation towards, and involvement with, others in contexts 
that arose out of specific efforts to communicate. That is, authenticity requires that we come to understand that communication, in all its instantiations, is the very medium of human freedom. This freedom is ours only when we face the risks accompanying our taking up the authentic responsibilities that increase our capacity to act, and which involve a recognition of the fundamental relationship that stands between our experience of ourselves and the participation of others. Responsibility, then, consists in perceiving our relations with others as the interactive contexts of a transformative recognition, and in doing our best to ensure that this transformation occurs.

\section{Notes}

1 For a well-known work dealing with the connection between Heidegger's critique of "principled" metaphysical thinking and how such thinking tends to justify a thoughtless conformity to the terms of public life, see Schürmann. For a work that examines the implications of Heidegger's thought with respect to the political priority of law, see Rickey. Rickey argues that Heidegger's politics is essentially a religious and mystical politics that remedies the meaninglessness of modern life by displacing the priority of democratic ideals expressed in positive law with the decrees of a charismatic leader who has the potential to reveal and realize the potential for meaningful involvement in community. For an article that deals with Heidegger's interpretation of the Anaximander fragment and this interpretation's contribution to contemporary thinking about the limits of positive and natural law, see Deville.

${ }^{2}$ For an excellent interpretation of Being and Time with regard to the question of how we ought to live, see Nicholson.

${ }^{3}$ For a critique of this nature, see Levinas.

${ }^{4}$ Questions about the constitution of community and the way in which an individual's relation to a particular community enables that individual's realization of their freedom have been a site of controversy in Martin Heidegger's work. On the one hand, Heidegger's personal, political past lays the foundation for claims that his association of Dasein's authentic possibility with a people, or Volk, is too essential and thus inevitably "Nationalistic." On the other hand, Heidegger's work is criticized for having no ethical or political content, and consequently having nothing to say about what constitutes community or how we human beings might best live together within one. For an article offering an overview of the issue of Heidegger and Nationalism, see Odysseos. She argues that rather than uncritically taking up its history, Dasein is tied to its particular community 
through a "critical" type of belonging that requires it to interpret handed down possibilities in light of the exigencies of its own time. For other works dealings with this question, see Ott, Farias, Lacoue-Labarthe, De Beistegui, Birmingham.

${ }^{5}$ For Sartre's account of the other as "contingent fact," see Being and Nothingness (474). A strict reading of Sartre's ontological position reveals that consciousness, or the "for itself," is affected by the other only when and if the other actually appears to consciousness. It is on the basis of the contingency of the other that Sartre presents the two fundamental attitudes of our relations to others as "failures"; we engage inauthentically with the other to the degree that we remain tied to the experience according to which the other is a contingent fact. At the same time, because the fact of the other realizes possibilities for us that are both our own and founded on the other's freedom, insofar as we understand ourselves in terms of possibilities constituted by our fundamental openness to others, the other ceases to be a contingent fact and becomes constitutive of our understanding of ourselves as free self-responsible selves. Sartre points to the relationship between the undeniable experience of the other and self-responsibility: "The lovers remain each one for himself in a total subjectivity; nothing comes to relieve them of their duty to make themselves exist each one for himself' (490, my italics). In other words, if the starting point is isolated consciousness, the demand that issues from it is precisely the demand to negotiate our co-responsibility for one another, a co-responsibility that for Sartre, as for Heidegger, is experienced in the very sharing of terms and expressive possibilities of language. For Sartre's account of language as "originally being-for others," see Being and Nothingness (485). For an account of why conflict does not found all social relations, and of the "conversion" necessary for the alternative (subject-subject) mode of relating to one another, see Rae. My claim of course, is not that Sartre's and Heidegger's position are the same, but, rather, that both positions lead to recognizing our responsibility to the other and our shared contexts, and that insofar as Sartre's account is more compatible with modern presuppositions about subjectivity, it offers a view of why interpersonal relations are sites in which we can begin to overcome modern prejudices about the nature of subjectivity, a preparation that is helpful for coming to respond to the demands of Heideggerian authenticity. To my mind, Heidegger's account is stronger because Sartre's account of authentic relations asks us to experience the other as subject, Heidegger's account explains why it is precisely our individuated experience that demands our negotiation with others as the medium of our self-realization.

${ }^{6}$ Jean-Luc Nancy notes that Sartre never "managed to do anything other more than coat the most classical individual-subject with a moral or sociological past" (4). While Nancy's account supports my interpretation of Sartre's subjectivism, I do think that Sartre nevertheless offers important insights into the nature of self-responsibility and freedom, and that these insights are compatible with my own account.

${ }^{7}$ Heidegger himself underscores the possibility of an ontological description of that which has moral implications. For example, he writes, "In the following analysis conscience will be taken as something which we have in advance theoretically, and it will be investigated in a purely existential manner, with fundamental ontology as our aim" (BT 313; SZ 268). 
${ }^{8}$ While my claim about the availability of freedom within community opens the possibility for criticism based on an overly essentialist reading of community, and the consequent dangers of various forms of oppression and exclusion that accompany such a reading, on my view, my analysis avoids such criticism in two basic ways. Firstly, I emphasize that my responsibility for a common world is a responsibility to identify and correct pervasive failures to recognize the claims of identity made by particular others. This dimension of responsibility corresponds to an open-ended diversity of claims to identity, and consequently to the impossibility of some essential dimension of community belonging. Secondly, because I identify "communicative structures" as constitutive of community and claim that freedom in community depends on whether or not we recognize such structures as communicating identities, the possibility of misrecognizing, on the part of one community, the claims to identity expressed by other communities, through either shared or distinct communicative structures, is diminished to the degree that freedom is attained within that particular community. Freedom depends on the degree to which a social structure is recognized as a public and collective way of recognizing legitimate expressions of identity.

${ }^{9}$ My position is at odds with some feminist interpretations of Heidegger that claim Heidegger's account of authenticity overlooks the significance of its birth (see Guenther; Irigaray).The thrust of these is that Heidegger overemphasizes Dasein's agency and disregards the gift of birth given by the mother. This important issue is, I think, best attended to from within authenticity as Heidegger presents it, and as I am interpreting it. Since, on my account, authenticity consists in responding appropriately to one's relations with others and enacting one's identity through these relations, it is within an attempt to be authentic that a relation to the gift of birth can be most appropriately attended to. For an account of authenticity that supports my view, see Russon.

${ }^{10}$ Put otherwise, I am claiming that Dasein overcomes its fallenness when it experiences the contingent and intersubjectively constituted character of the terms of "the They." This means, in effect, that Dasein regains its own authentic individuatedness only by properly recognizing the dynamic through which the terms of "the They" are availed to it. For Heidegger's comments on the "sameness" of inauthentic and authentic Dasein see (BT 168; SZ 130) and for Heidegger's comments on how this same modification is equally modification of "idle talk" see (BT 213; $S Z$ 169). It is worth noting that, contra Sartre, for whom language is primarily a matter of Beingwith, Heidegger characterizes language as the medium through which we can, cooperatively, attend to "what is said-in-the-talk as such" (BT 212; SZ 168). For an account of how this attitude of disclosure amounts to a learning that is essential to our capacity to be ourselves, see Russon (104). In light of that discussion, one might consider the way in which the supplementary dimension of authenticity I am arguing for amounts to a kind of "learning-with."

${ }^{11}$ The factical relations to one another I have just referred to are grounded on the more originary relating at work in our Being-with. As Being-with, we can understand what any communication is about because we originally find ourselves by "hearing" either authentically or inauthentically: Listening to ... is Dasein's existential way of Being-open as Being-with for Others. Indeed, hearing constitutes the primary and authentic way in which Dasein is open for its ownmost potentiality-for-Being - as in hearing the voice of a friend whom every Dasein 
carries with it. Dasein hears because it understands. As Being-in-the-World with Others, a Being which understands, Dasein is "in thrall" to Dasein-with and to itself; and in this thralldom it "belongs" to these. Being-with develops in listening to one another [Aufeinander-hören], which can be done in several possible ways: following, going along with, and the privative modes of not-hearing, resisting, defying, and turning away. (BT 206; SZ 163)

12 Heidegger's account of conscience is illustrative of how the possibility of authenticity belonging to individual Dasein requires that it respond adequately to others for the "existentiell," or ontic, modification of the "they" (BT 312;SZ 267) accomplished in Resoluteness [Erschlossenheit].

13 Different authors address the fact that while "conscience" and "guilt" in Heidegger's work have nothing to do with anything like a prescriptive and normative ethics, his thought on these issues can nonetheless contribute to ethical thinking. For example, see Dreyfus, Olafson. For an account that explains why our self-realization is perpetually inadequate and marked by a certain "loss," see Russon (99). Russon also notes that Sartre's account of vertigo describes the "undecidability" of the situation that gives rise to this loss, but that Heidegger's account allows us to respond to the impossibility of promising in the name of our future selves through anticipatory resoluteness (98-99). This hints at why Sartre's account can inform an approach to the ontological constitution of ourselves that Heidegger describes. On Heidegger's account the insufficiencies and challenges that define us are the medium of our authentic ownership of ourselves, and he is able to show that this is the case because Dasein's authentic self-realization involves owning up to all aspects of human reality, while Sartre's account of consciousness begins from the challenges that beset human reality without thinking about the condition of possibility of such challenges.

${ }^{14}$ Here, I am echoing Heidegger's own account of resoluteness: "The resolution is precisely the disclosive projection and determination of what is factically possible at the time" (BT 345; $S Z$ 298). While Being-guilty is most often interpreted as a way of pointing to the fact that Dasein is essentially constituted by possibilities that it in fact did not take up, and for which it must consequently take responsibility and be answerable, what I am suggesting here is that because Being-guilty requires that Dasein take responsibility for its having chosen one worldly possibility - such that it exists in the fallen world of the "They" - the specific terms into which it falls play a constructive and positive role in revealing how Dasein can begin to responsibly and authentically make the self it already is its own because these terms have the capacity to reveal to Dasein how it ought to treat others. For an interpretation of "primordial Being-guilty" that takes the line I described, see Miyasaki.

${ }^{15}$ We might note here that the attestation of conscience, achievable in isolation, is necessarily an acknowledgement of the incompleteness of Dasein's isolation, an incompleteness that can itself be owned up to be recognizing the necessity of the intersubjectively-constituted world to one's own projects see (BT 334; SZ 288). 
${ }^{16}$ In "Understanding the Appeal and Guilt," Heidegger writes:

Although it has not laid that basis itself, it reposes in the weight of it, which is made manifest to it as a burden by Dasein's mood" (BT 330; SZ 284). Heidegger is here referring to the basic mood of anxiety through which it is revealed to Dasein that it really is its thrown self and will never be other than itself. Having to be oneself is experienced as a burden because it is not something that Dasein chose and it is simultaneously something that Dasein must take responsibility for by enacting: "In having a mood, Dasein is always disclosed moodwise as that entity to which it has been delivered over in its Being: and in this way it has been delivered over to the Being which, in existing, it has to be. $(B T 173 ; S Z 134)$

${ }^{17}$ Dreyfus illustrates this point clearly stating:

For the Greeks, what showed up were heroes and slaves; for the Christians, they were saints and sinners. There could not have been saints in Ancient Greece; at best there could only have been weak people who let others walk all over them. Likewise, there could not have been Greek-style heroes in the Middle Ages. Such people would have been regarded as prideful sinners who disrupted society by denying their dependence on God and encouraging everyone to depend on them instead. ("Heidegger's Ontology of Art" 415)

Dreyfus is here making the point in relation Heidegger's 1936 essay, "The Origin of the Work of Art." Nevertheless, the description applies aptly to what I am claiming is implicit in Being and Time.

${ }^{18}$ For a more extended analysis of the role of communication in Being and Time, and the relationship between communication and community, see Powell.

${ }^{19}$ My reference to "terms of recognition" is an implicit reference to discourse or logos, and therefore a reference to how "things," as well as people, appear in the world. In this work, I am specifically concerned with establishing the way that others appear to a particular Dasein through shared terms, and through the communication that constitutes and enables these terms. This discussion would be fortified by a more focused examination of the relationship between things and language. In particular, an examination of Heidegger's treatment of phenomenology in the Introduction to Being and Time would be helpful.

${ }^{20}$ Heidegger explains that various modes of Dasein-with-being missing, being away, being among others, for example - are "possible only because Dasein as Being-with lets the Daseinwith of others be encountered in its world" (BT 157; SZ 121).

${ }^{21}$ To acknowledge the cooperative dimension of relations sometimes means understanding how it can be a lack of sheer reciprocity that in fact constitutes my relations and possibility. A parentchild or teacher-student relationship are examples of, if not lack of reciprocity, then a relationship in which reciprocity is not a matter of equal exchange. 
${ }^{22}$ The term "failure" is considered by some to be a loaded term when used in reference to Heidegger's work, in part because of its implicit references to Heidegger's "moral failure," and in part because the idea of a failure at the level of concern can be connected to a thinking of the ontological dimension of Dasein's experience in the concernful world. For texts dealing with Heidegger's moral failure in light of his involvement with the National Socialist party, see Lacoue-Labarthe, Janicaud, Krell. For an account of the role that "failure" plays in Heidegger's text, both with respect to Dasein's concernful dealing with equipment, and with respect to conscience, see Marder.

${ }^{23}$ Jacobson's article helpfully describes the way that Dasein's ability to be a public being is something that must be accomplished; only by first developing an ability to be at home in the world can Dasein the develop the ability to navigate the impersonal structures of communication that are pervasive in modern life. Her account supplements my own by emphasizing that Dasein's ability to be in the world is always a particular accomplishment and, as such, is open to transformation.

24 "Leaping-ahead" resonates with Heidegger's account of care and, thereby underscores the fact that Dasein must attend to relations with others in order to attend to its own authentic projects. Heidegger's claim, "Dasein is always 'beyond itself' [über sich hinaus], not as a way of behaving towards other entities which it is not, but as Being toward the potentiality-for-Being which it is itself" (BT 236; SZ 192) is suggestive of the view that Dasein's authenticity requires that it attend to others in the mode of Leaping-ahead, rather than to beings understood as what "it is not" so that it can properly orient itself towards its "ownmost" possibility of Being, of which others are constitutive. Involved in this mode of attending is a relation to the other as equally constituted by care, that is, by a singular experience of the world that is irreducible to mine.

${ }^{25}$ I use the masculine pronoun to maintain consistency between Heidegger's text and my commentary.

${ }^{26}$ While in the previous section, I do not address the issue of Dasein's "responsibility" to the other in the world, Heidegger himself points to this issue at the beginning of §58. He explains that the ordinary conception of guilt refers to being the basis or ground of something lacking in the other such that "this kind of lacking is a failure to satisfy some requirement which applies to one's existent Being with others" (BT 328; SZ/282). Heidegger is addressing the issue of what Dasein may "owe" to other Dasein on the basis of how Dasein exists in the world with others. While Heidegger is careful to distinguish the ontological meaning of Being-guilty from what Dasein may owe to others on the basis of any concernful dealing, as I see it, the fact that the relationships between Dasein-with and Being-with is what leads to the worldly structures within which Dasein comes to owe something to others connects to the two domains of guilt without reducing one to the other. Heidegger is concerned with distinguishing between ways of being that belong to Dasein, and that which belongs to the existential structure of Dasein, or, in his words, what amounts to an ontological attribute of Dasein, and this concern does not preclude thinking about the connection between differing dimensions of Dasein. 
${ }^{27}$ For Sartre, in experiences of desire we adopt a fundamental attitude according to which we will enact our relations to others and our participation in the world. This fundamental attitude, Sartre writes:

can remain hidden just as a skeleton is veiled by the flesh which surrounds it; in fact this is what usually happens. The contingency of bodies, the structure of the original project which I am, the history which I historicize can usually determine the sexual attitude to remain implicit, inside more complex conduct. (528)

My account emphasizes the disclosive nature of our relations with others. An alternative interpretation might focus on the ways in which we take up our relations with others in "bad faith," or on how to negotiate our tendency to act in bad faith in order to properly carry out our relations with other. For an example of this alternative, see Rae.

${ }^{28}$ For Sartre, as for Heidegger, a world does not exist without human beings. More specifically, for Sartre, a world comes into being when a for-itself or self-consciousness, disrupts the indistinguishable and massive in-itself, or concrete existence as such, by distinguishing one thing from another through the process of negation (see Morin 37-43).

\section{Works Cited}

Birmingham, Peg. "The Time of the Political." Graduate Faculty Philosophy Journal 14, no. 215, no.1 (1991): 25-45.

De Beistegui, Miguel. Heidegger and the Political: Dystopias. London: Routledge, 1997.

Deville, Jacques. "Rethinking the Notion of "Higher Law': Heidegger and Derrida on the Anaximander Fragments." Law Critique 20 (2009): 59-78.

Dreyfus, Hubert L. Being-in-the-World: A Commentary of Heidegger's Being and Time, Division 1. Cambridge MA: The MIT Press, 1991.

—. "Heidegger's Ontology of Art." A Companion to Heidegger. Eds. Hubert L. Dreyfus and Mark A. Wrathall. Cambridge: Blackwell Publishing Ltd, 2005. 407-419.

Farias, Victor. Heidegger and Nazism. Trans. P. Burnell and G. R. Ricci. Philadelphia: Temple University Press, 1987.

Guenther, Lisa. "Being-from-others: Reading Heidegger after Cavarero." Hypatia 23, no. 1 (2008): 99-118.

Irigaray, Luce. The Forgetting of Air in Martin Heidegger. Trans. Mary Beth Mader. Austin: University of Texas Press, 1999. 
Heidegger, Martin. Being and Time. Trans. John Macquarrie and Edward Robinson. San Francisco: HarperCollins Publishers. 1962.

-. Ontology: The Hermeneutics of Facticity. Trans. John M. Burns. Bloomington: Indiana University Press, 1999.

Jacobson, Kirsten. "The Experience of Home and the Space of Citizenship." The Southern Journal of Philosophy 48, no. 3 (2010): 219-45.

Janicaud, Dominique. The Shadow of that Thought: Heidegger and the Question of Politics. Trans. Michael Gendre. Evanston: Northwestern University Press, 1996.

Krell, David. Daimon Life: Heidegger and Life Philosophy. Bloomington: Indiana University Press, 1992.

Lacoue-Labarthe, Philipe. Typography: Mimesis, Philosophy, Politics, Trans. C. Fynsk. Stanford University Press, 1998.

- Heidegger, Art, Politics: The Fiction of the Political. Trans. Chris Turner. Oxford: Basil Blackwell, 1990.

Levinas, Emmanuel. "Is Ontology Fundamental?" Basic Philosophical Writings. Ed. Adriaan Theodoor Peperzak, Simon Critchley, and Robert Bernasconi. Indianapolis: Indiana University Press, 1996. 1-10.

Marder, Michael. 'Heidegger's 'Phenomenology of Failure' in Sein und Zeit." Philosophy Today 51, no. 1 (2007): 69-78.

Morin, Marie-Eve. "Thinking Things: Heidegger, Sartre, Nancy." Sartre Studies International 12, no. 2 (2009): 35-53.

Miyasaki, Donovan. "A Ground for Ethics in Heidegger's Being and Time." Journal of the British Society for Phenomenology 38, no 3 (2007): 261-79.

Nancy, Jean-Luc. The Inoperative Community. Trans. Peter Connor, Lisa Garbus, Michael Holland, and Simona Sawhney. Minneapolis: University of Minnesota Press. 1991.

Nicholson, Graeme. Justifying our Existence: An Essay in Applied Phenomenology. Toronto: University of Toronto Press, 2009.

Odysseos, Louisa. "Constituting Community: Heidegger, Mimesis and Critical Belonging." Critical Review of International Social and Political Philosophy 12, no. 1 (2009): 37-61. 
Olafson, Frederick. Heidegger and the Ground of Ethics: A Study of Mitsein. Cambridge: Cambridge University Press, 1998.

Ott, Hugo. Martin Heidegger: A Political Life. Trans A. Bluenden. New York: Basic Books, 1993.

Powell, Jeffrey. "Heidegger and the Communicative World." Research in Phenomenology 40 (2010): 55-71.

Rae, Gavin. "Sartre and the Other: Conflict, Conversation, Language and the "We." Sartre Studies International 15, no. 2 (2009): 54-77.

Rickey, Christopher. Revolutionary Saints: Heidegger, National Socialism, and Antinomian Politics. Pennsylvania: The Pennsylvania State University Press, 2002.

Russon, John. "The Self as Resolution: Heidegger, Derrida and the Intimacy of the Question of the Meaning of Being." Research in Phenomenology 38 (2008): 90- 110.

Sartre, Jean-Paul. Being and Nothingness: A Phenomenological Essay on Ontology. Trans. Hazel Barnes. New York: Washington Square Press. 1956.

Schürmann, Reiner. Heidegger on Being and Acting: From Principles to Anarchy. Trans. Christine-Marie Gross. Bloomington: Indiana University Press, 1987. 